\title{
Basic Elements: Cash Flow, Tax, Expectation, Cost of Capital, Value
}

\subsection{Fundamental Terms}

Valuation is being talked about everywhere. Finance experts, CPAs, investment bankers, and business consultants are discussing the advantages and disadvantages of discounted cash flow (DCF) methods since years. This book takes part in the discussion, and intends to make a theoretical contribution to it.

Those who get involved with the DCF approach will inevitably run into a number of reoccurring terms. It is typically said that the valuation of a firm involves the discounting

- of its future payment surpluses

- after consideration of taxes

- using the appropriate cost of capital.

Three things must obviously be clarified: firstly, it must be understood what payment surpluses are; secondly, a proper understanding of the taxes taken into consideration is needed; and thirdly, information about the cost of capital is required.

The payment surpluses, which are to be discounted, are also called cash flows. Nowhere in the literature this term is clearly defined. So one can be certain that no two economists speaking about cash flows will have one and the same thing in mind. The reader of this book might expect that we will go into elaborate detail on how cash flows are determined. We will disappoint these hopes. Essentially, we will be limiting ourselves to working out the difference between gross cash flows and free cash flows.

It is relatively clear what one means when speaking of taxes while doing a business valuation. The lawmakers leave no doubt as to which payments are due to him. Furthermore, it is known to all those involved in business valuation that taxes on profit are to be taken into particular consideration. Finally, every evaluator 
knows that there are such taxes on the corporate as well as on the private level of business. In Germany, for instance, one must think about corporate and trade tax on the business level, and about income tax on the level of the financiers. This book is not, however, intended for readers who are interested in the details of a particular national tax system. Therefore, we do not plan to individually present the British, German, or US tax systems. On the contrary, we will base our considerations on a stylized tax system. Some readers may have different expectations regarding this point as well.

As a rule it remains rather unclear in business valuation what is meant by cost of capital. Even those who consult the relevant literature will not find, in our opinion, any precise definition of the term. This brings us head-on with the question as to what cost of capital is.

Every theory of business valuation is based on a model. Such a model possesses characteristics which we will describe here. In the following sections, we will deal with cash flows, taxes, and cost of capital in some more detail.

\subsubsection{Cash Flows}

To make use of a DCF approach, the evaluator must estimate the company's future cash flows. This leads to two clearly separate problems. The first question asks what it actually is that must be estimated ("What are cash flows?"), and the other concerns their amount ("How are future cash flows being estimated?"). The first question is a matter of definition, whereas the second involves a prognosis. We are concentrating on the first issue.

Gross Cash Flow By gross cash flows we understand the payment surpluses, which are generated through regular business operations. They can either be paid to the financiers, or kept within the company, and so be realized as investments. When referring to the financiers, we are speaking about the shareholders on the one hand, and the debt holders on the other. The payments to the financiers involve either interest repayments or debt service, or dividends and capital reductions. In the case that taxes have not yet been deducted from the gross cash flow, we are speaking about gross cash flow before taxes, see Table 2.1.

Table 2.1 From EBIT to gross and free cash flow

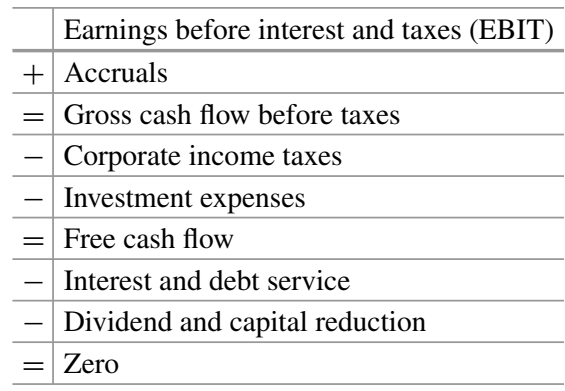


Those who need to determine the gross cash flow for an already past accounting year of an existing business normally fall back upon the firm's annual financial statements. They study balance sheets, income statements and, most likely, cash flow statements as well. The way in which one needs to deal with these individually depends heavily upon which legal provisions were used to draw up the annual reports, and on how the existing law structures in place were used by the managers of the firm. It makes a big difference if we are looking at a German corporation, which submits a financial statement according to the total cost format, and in doing so follows the IFRS (International Financial Reporting Standards), or if it concerns a US American company, which concludes according to the cost of sales format and pays heed to the US-GAAP (Generally Accepted Accounting Principles). No uniform procedure can be described for calculating the gross cash flow of the past business year for both firms. Thus, we may justify why we will not elaborate here on the determination of gross cash flows.

Free Cash Flow Companies must continually invest if they want to stay competitive. These investments are usually subdivided into expansion and replacement investments. Expansion investments ensure the increase of capacities and are indispensable if the firm should grow. The replacement investments, in contrast, ensure the furtherance of the status quo. They are, hence, usually fixed according to the accruals. We are working under the assumption that the firm being valued is intending on making investments in every period. Sensibly enough, those are only investment projects that are attractive from an economic perspective.

We refer to the difference between gross cash flow after taxes and the amount of investment as the firm's free cash flow. This amount can be paid out to the firm's financiers, namely the shareholders and the creditors.

Projection of Cash Flows The practically engaged evaluator must spend a considerable amount of her precious time on the prognosis of future cash flows: we already mentioned that it is not the historical payment surpluses that matter to the firm being valued, but rather the cash flows that it will yield in the future. The work of theoretically based finance experts is generally of limited use for this important activity. We will not be discussing practical questions related to the prognosis of cash flows in this book at all.

\subsubsection{Taxes}

Income-, Value-Based- and Sales Tax As a matter of fact, a company is not dealing with only one single type of tax. We usually distinguish between income taxes (for example, personal income tax), value-based taxes (for example, realestate tax), and sales taxes (for example, value-added tax and numerous others). For the purposes, which we are aiming towards in this book, the sales taxes do not play any significant role - they simply depict a component of the cash flow and are otherwise of no further interest. Value-based taxes are also not usually discussed 
in-depth within the framework of literature on valuation of firms. We follow this convention and are concentrating largely just on income taxes.

Business- and Personal Tax Income tax is imposed on the firm level, as well as upon the shareholder level. In the first case we will speak about a corporate income tax, and in the second about personal income tax. In the USA, a corporate income tax is to be thought of with business tax; in addition, income tax accrues on the shareholder level (on the federal and local levels).

Our readers should not expect that we will go into detail on either the US American or other national tax systems. In this book we do not intend to treat the particularities of national tax laws with their immeasurable details. We have two reasons for this. For one, national tax laws are subject to constant changes. Every such change would require a new edition of the book. We are concerned here with a general theory, which is able to deal with the principle characteristics of tax law. Secondly, we would thus not only have to deal with the integration of one single tax law into the DCF approach, but rather of the tax laws of every important industrial nation around the world. This would, however, overstep the intended breadth of the book.

Those who identify the value of a firm with the marginal price from the viewpoint of a normal person will have no other alternative than to consider the business as well as the personal taxes. ${ }^{1}$

Features of a Tax In order to more exactly identify a tax, three characteristics are to be kept in mind, which can be observed in every type of tax. Thus, the next pertinent question is, who must pay the taxes: this is the tax subject. The tax base expresses how the object of taxation is quantified. And finally, the tax scale describes the functional relation between the tax due and the tax base. We are characterizing the corporate income tax and the personal income tax as well in the following with regard to the three named characteristics.

Tax Subject The tax subject describes who has to pay the taxes. In the case of the corporate income tax it is the firm, which is to be valued, while the object of taxation are the business activities of the firm. In the case of the personal income tax it is the financiers (owner as well as debt holder) who are the tax subject. The object of taxation are then the income streams from the firm or other activities particularly on the capital market.

Tax Base The corporate income tax is calculated according to an amount that is commonly referred to as profit. If one thinks of the US American corporate income tax, one effectively envisages the tax profit. Regarding the personal income tax the gross income minus some expenses form the tax base.

\footnotetext{
${ }^{1}$ In Germany that corresponds to the viewpoint of the profession of chartered accountants, see Institut der Wirtschaftsprüfer in Deutschland (2008).
} 
Tax Scale If the tax scale is applied to the tax base, the tax due is established. Linear and nonlinear scale functions are usually observed. We will be working with a linear tax scale and take neither allowances nor exemption thresholds into consideration. The tax due is ascertained by multiplying the tax base by a tax rate, which we assume is independent of the tax base.

Such an assumption is obviously unrealistic. We do not know any income tax worldwide where the tax scale is certain, an allowance (as small as possible) causes the tax function to be nonlinear. In the recent past there has been done some research on nonlinear tax scales and valuation but the number of pertinent papers can be counted on the one hand. Hence, we will uphold linearity.

What is more, we will assume that the tax rate at the time of valuation is known and absolutely unchangeable! That is a far-reaching assumption, and we are entirely aware of the resulting limitations. We feel that uncertain tax rates have not been discussed in the literature until now, besides in isolated cases, and not at all in the DCF approaches to date. There is a gulf here between theory and practice that we will not be able to bridge over in this book. The practice-orientated reader will regard our course of action as rather far off from reality. In this book, we will later speak a lot about certain and uncertain tax advantages. If we state this here, and then later follow through on it, the manager may suspect-not unjustifiably-the most important source of uncertainty to be future unknown tax rates. Regardless, all known DCF approaches rule out just this source of uncertainty before we even begin. We still have a wide field of research ahead of us.

\subsubsection{Cost of Capital}

We do not know if this book's reader is particularly interested in a precise definition of cost of capital. We are convinced that for a theoretical debate of the DCF methods, it is of considerable importance. We would be happy, if our reader would be understanding of this, or would at least develop such an understanding in reading the book.

Cost of Capital as Returns In order to make our considerations more understandable, let us leave out uncertainty. The company that is to be valued may promise certain cash flows for the future, which we denote by $F C F_{1}, F C F_{2}, \ldots$. We will gain a preliminary understanding of the notion of cost of capital, when we ask about the role the cost of capital should play. It serves for the determination of the company's value. For this purpose the certain cash flows are discounted with the (probably time-dependent) cost of capital. A valuation equation would look, for example, like the following:

$$
V_{0}=\frac{F C F_{1}}{1+k_{0}}+\frac{F C F_{2}}{\left(1+k_{0}\right)\left(1+k_{1}\right)}+\ldots
$$


where $k_{0}, k_{1}, \ldots$ are the cost of capital of the zeroth, first, and all further periods and $V_{0}$ is the company's value at time $t=0$. In the course of our book, we will see that we repeatedly need an equation for the future value of firm $V_{t}$ at $t>0$. It would be convenient if Eq. (2.1) could be used analogously at later times. For that we had

$$
V_{t}=\frac{F C F_{t+1}}{1+k_{t}}+\frac{F C F_{t+2}}{\left(1+k_{t}\right)\left(1+k_{t+1}\right)}+\ldots
$$

And one obviously gains a computational provision from which such future business values are established.

By assuming $V_{n \rightarrow \infty}=0$ Eq. (2.2) can be used to infer the relation

$$
k_{t}=\text { Def } \frac{F C F_{t+1}+V_{t+1}}{V_{t}}-1,
$$

that gives us a basis for a precise definition of the cost of capital as future return. The economic intuition of such a definition is most easily revealed if one imagines that an investor at time $t$ acquires an asset for the price $V_{t}$. At time $t+1$, this asset may yield a cash flow (a dividend) of $F C F_{t+1}$ and immediately afterwards be sold again for the price of $V_{t+1}$. The return of such an action is then precisely given through the definition (2.3).

Obviously, the definition of the cost of capital (2.3) and the application of the valuation Eq. (2.2) for all times $t=0,1, \ldots$ are two statements, which are logically equivalent to each other. If it is decided to understand cost of capital as return in the sense of definition (2.3), then the valuation statement (2.2) is straightforward. The inversion is true as well: starting out from the valuation statement (2.2), it is implied that the suitable cost of capital are indeed the returns. This simple idea will be the red thread throughout our presentation.

Cost of Capital as Yields Let us suppose for a moment that it is possible at time $t$ to pay a price $P_{t, s}$ and in return to earn nothing else than a dividend in amount of $F C F_{s}$ (in which $s>t$ ). If under $\frac{1}{\left(1+\kappa_{t, s}\right)^{s-t}}$ the price of a monetary unit is understood that is to be paid at time $t$ and which is due at time $s$, then we designate $\kappa_{t, s}$ as yield. The following relations are valid for such yields:

$$
\begin{aligned}
P_{t, t+1} & =\frac{F C F_{t+1}}{1+\kappa_{t, t+1}} \\
P_{t, t+2} & =\frac{F C F_{t+2}}{\left(1+\kappa_{t, t+2}\right)^{2}}
\end{aligned}
$$


The value of a firm at time $t$, which promises dividends at times $s=t+1, \ldots$, could be (again assuming $V_{n \rightarrow \infty}=0$ ) written in the form

$$
V_{t}=\frac{F C F_{t+1}}{1+\kappa_{t, t+1}}+\frac{F C F_{t+2}}{\left(1+\kappa_{t, t+2}\right)^{2}}+\ldots
$$

But to the contrary of the valuation Eq. (2.2), the formal structure of (2.4) cannot be used at time $t+1$. The yields of time $t$ will certainly be different from the yields one period later, i.e.,

$$
V_{t+1}=\frac{F C F_{t+2}}{1+\underbrace{\kappa_{t+1, t+2}}_{\stackrel{?}{=} \kappa_{t, t+1}}}+\frac{F C F_{t+3}}{(1+\underbrace{\kappa_{t+1, t+3}}_{\stackrel{?}{=} \kappa_{t, t+2}})^{2}}+\ldots
$$

For our purpose it is only appropriate to understand cost of capital as returns and not as yields.

Those who are used to work with empirical data will not hesitate to agree with our definition of the term. At any rate, in all empirical examinations known to us, returns are always determined when cost of capital should be calculated. It is much more difficult to estimate yields or discount rates (to say nothing of risk-neutral probabilities which will be introduced shortly). Therefore, defining cost of capital as returns is suitable.

The question must now be asked how the concept of cost of capital can be defined under uncertainty. We will first be able to answer this question more exactly in a later section of the book.

\subsubsection{Time}

In order to illustrate a basic idea of the DCF model, let us use an agricultural analogy: a cow is worth as much milk as it gives. For businesses and their market value, that means a firm's market value is orientated on future payment surpluses. If this is accepted, then the question arises as to how long a firm stays alive.

Life span So long as nothing to the contrary is known, one cannot go wrong in assuming that the firm will be around for more than a year. Such a vague supposition is of little help. As a rule it can be said that firms are set up for the long-run, and that most investors involved in the purchase of companies-and who fall back on procedures of business valuation for this means - have an investment horizon, which clearly overstretches 1 year. However, we are running in circles, because whether we assume the business will survive for more than a year, or think that it will remain active until "however long," the picture is still pretty unclear. 
Fig. 2.1 Prices are always ex cash flow

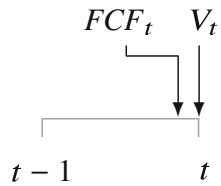

Coming to a head, we question whether it should be suggested in business valuation that firms either have a finite life span, or are eternally active. It seems rather bizarre at first glance to conceive that firms live infinitely.

Regardless, there are worthwhile arguments in favor of the fiction of the eternally living company. When valuing a firm, which only has a limited life span, its end-date must be determined. An exact answer-apart from very few exceptions-would be impossible. Moreover, on the last day of the firm's history, a residual value will be paid to the owners. If you wanted to answer the question as to how the firm's residual value is to be determined, you would have to fall back upon the subsequent payments to be attained-that certainly does not fit into our assumption anymore that the world is just about to end. That is why an exact calculation of the residual value would likewise not succeed. If it can also be shown that it makes no difference worth mentioning whether you operate under the premises of a business life span of, let us say, 30 years, or that the business is incessantly active, then the fiction of an perpetually active firm, albeit objectively false, can be justified for the sake of convenience. $^{2}$

What we want to get across to our readers is to the effect that we are working on the basis of an investment horizon of many periods, and do not yet want to conclusively commit to either a finite (denoted by $T$ ) or an infinite horizon. Since in actuality, were our theory really to be put into practice, we should suggest an infinite planning horizon.

Trade- and Payment Dates It is necessary to specify the trade- and payment dates of our model. An investor, who owns a share gets the cash flow at just the right second before $t$ (see Fig. 2.1). If she sells this security at $t$, then the buyer always pays a "price ex cash flow." Although this arrangement is fully normal within the framework of the DCF approach, we explicitly stress it here. It leads to not being able to illustrate particular trading strategies in our model. For dividend stripping, for instance, a share would have to be bought immediately before the dividend payment-a comportment our model does not allow.

Continuous or Discrete Time We have decided that the firm to be valued, will be observed over a time frame of several periods. But should our model now be continuous time or discrete time?

\footnotetext{
${ }^{2}$ If cost of capital in the amount of $10 \%$ and constant cash flows are implied, then the first 30 years explain virtually $95 \%$ of the firm's total value.
} 
In order to make the difference between both types of models clear, let us look at a firm with a finite life span of $T$ years. If we use a time-screen, in which there are only times $t=0$ (today), $t=1$ (1 year from today), $\ldots, t=T$ ( $T$ years from today), then the model's framework is discrete. We could, without question, divide up each year into quarters, months, weeks, or even days. In the last case, we would run the time index $t$ from 0 to $365 T$, and since the days are countable, we would still be dealing with a discrete model. The more minutely we choose to divide up the time, that many more sub-periods there are in a year. But only after we let the number of annual sub-periods grow beyond all limits, so that the number of time intervals can no longer be counted, would we be looking at a continuous time model.

After we have gotten a good enough idea as to where the difference between discrete time and continuous time models lies, we turn back again to the question as to which type of model we should choose. In so doing, we find out that we do not have any criteria by which we can ascertain the advantages and disadvantages of one type or another.

One could get the idea that this continuous modeling is unpractical, since just as the cow cannot be continually milked, neither can a firm pay out dividends incessantly. So, let us instead say that the cow is milked once a day, and a corporation pays dividends once a year, for instance. Such intermittent events can, however, be included within a continuous time model, as well as a discrete time model. We must think of something else.

In the modern finance literature, continuous time models have experienced a notable boom. They are much more popular than discrete models. But the mathematical tools required in the continuous time models are by far more demanding compared to those, which can be used in discrete time models. From our experience, new economical understanding in valuation of firms is not gained through the assumption of a continuous time world. In this book we always apply the framework of a discrete time model. This is purely and solely for practical reasons.

Distinguishing the current time $t=0$ (present) from the future $t=1,2 \ldots, T$, the ending time $T$ as seen from today's perspective can or cannot be infinitely far off. The length of a time interval is not dependent upon the situation in which our model will be used. Intervals of 1 year are typically the case.

\subsubsection{Problems}

1. Let the world end the day after tomorrow, $T=2$. Assume that $F C F_{2}=100$ is certain, but $\widetilde{F C F}_{1}$ is uncertain with $\mathrm{E}\left[\widetilde{F C F}_{1}\right]=100$. The riskless rate is $r_{f}=5 \%$. We now show that yields and cost of capital cover different economic terms.

(a) Assume that the yield for the first cash flow is $\kappa_{0,1}=10 \%$. Evaluate the company and determine the cost of capital $k_{0}$. 
(b) Assume that the cost of capital for the first cash flow is $k_{0}=10 \%$. Evaluate the company and determine the yield $\kappa_{0,1}$.

2. The reference point of our definition of yields was given by the time $t$. If we would have used time $t+1$ the corresponding equation would read

$$
P_{t+1, t+2}=\frac{F C F_{t+2}}{1+\kappa_{t+1, t+2}} \text {. }
$$

Prove that there is an opportunity for the investor to get infinitely rich (a so-called arbitrage opportunity) if

$$
\left(1+\kappa_{t, t+1}\right)\left(1+\kappa_{t+1, t+2}\right)=\left(1+\kappa_{t, t+2}\right)^{2}
$$

does not hold.

\subsection{Conditional Expectation}

As the evaluator of a firm, we find ourselves at time $t=0$, that is, in the present. The valuation of firms is taking place today, and it is not necessary to worry about how our knowledge about the object of valuation will increase over time. Although we cannot, so to speak, move ourselves out of the present, let us still consider what we know today, and what we will know in the future. We do not clarify how our knowledge is increasing, but rather only how the additional knowledge is dealt with and what consequences that has for the valuation of a company. This requires the understanding of uncertainty and the notion of conditional expectation.

\subsubsection{Uncertainty and Information}

We begin with the hardly surprising announcement that the future is uncertain. How now? For the variables analyzed by the evaluator, it means that today it still is not known what those variables will be. It is not known how many liters of milk the cow will produce tomorrow. It cannot exactly be said what the cash flow of the firm to be valued will be in 3 years. Instead, there exist many possibilities. We also speak of events, which can influence the amount of the cash flows. Uncertainty in relation to the cash flow is marked by adding a tilde to its symbol,

$$
\widetilde{F C F}_{t} \text {. }
$$

This type of notation is certainly out of fashion: In many papers and almost all textbooks random variables are nowadays not identified by a particular symbol like the tilde. From a typographical point of view this increases readability. But we believe that for someone who must learn the difference between a random value and a deterministic number it is of great help if the random variable has a clear and 
visible label. There are transformations that are allowed with deterministic numbers and that fail with random variables ${ }^{3}$ — without a unique label this can lead to serious errors. Therefore, we will persist on using the tilde.

States of Nature This representation leaves us in the dark as to what the interested variable is dependent upon. In fact, it is so that we foresee various possible states of nature. Such states could be described, for example, through product's market shares, or unemployment quotas or other variables. The cash flow would then be dependent upon however defined state variables denoted by $\omega$. If we do not refer to the entire random variable but to the cash flow in one particular state, we use the notation

$$
\widetilde{F C F}_{t}(\omega) \text {. }
$$

There are theoretical as well as practical reasons for our not making use of this detailed notation in the following, but instead only using the more simple spelling.

So we will make no statements in our theory at all about whether the number of the possible future states is finite or infinite. Rather, we simply leave it open, as to whether the state space is discrete or continuous. The formal techniques for dealing with continuous state spaces are more complicated than the instruments needed for the analysis of a discrete state space. We are trying to avoid wasting energy as much as possible here.

From our experience, every evaluator gives up making statements about future states of the world. One tries in practice to determine the expectations of the established quantities. And anticipated cash flows, or anticipated returns, are approximately estimated in such a way so that they do not need to rely upon the state-contingent quantities. Then why should we not try to avoid these details in our theory?

For both these reasons, we will in the future hold back the contingency of uncertain variables from states of the world, and will not further clarify the structure of the uncertainty.

Notation In order to make ourselves understood, we must introduce a few mathematical variables into the discussion. In so doing, we will use the notation common in current finance literature. The reader who is not used to this, may possibly ask at first why we did not try for a less exacting notation. The formal notation that we are now going to introduce, does in fact take some time to get used to, but is in no way so complicated that one should get scared off. It presents a straightforward and very compact notation for the facts, which need to be described in clarity. We therefore ask our readers to make the effort to carefully comprehend our notation. We promise on our part to make every possible effort to present the relations as simply as they are.

${ }^{3}$ For example, see footnote 10 in Sect. 2.3.2. 
Let us now concentrate on, for example, the cash flow, which the firm will yield at time $t=3$, so $\widetilde{F C F}_{3}$. The evaluator will know something more about this uncertain cash flow at time $t=2$ than at time $t=1$. When we are speaking about the expected cash flow from the third year and want to be precise, we must explain which state of information we are basing ourselves on. We denote the prospective on-hand information at time $t=1$ as $\mathcal{F}_{1}$. The expression

$$
\mathrm{E}\left[\widetilde{F C F}_{3} \mid \mathcal{F}_{1}\right]
$$

describes how high the evaluator's expectations will be about the cash flow of time $t=3$ from today's presumption of the state of information at time $t=1$. If the investor uses her probable knowledge at time $t=2$, she will have a more differentiated view of the third year's cash flow. This differentiated view is described through the conditional expectation

$$
\mathrm{E}\left[\widetilde{F C F}_{3} \mid \mathcal{F}_{2}\right]
$$

How is that to be read? The expression describes what the investor today believes she will know about the cash flow at time $t=3$ in 2 years. So you see, what at first glance appears to be a somewhat complicated notation, allows for a very compact notation of facts. Facts, that anyone can only painstakingly present verbally. Mathematically, the expression

$$
\mathrm{E}\left[\widetilde{F C F}_{t} \mid \mathcal{F}_{s}\right]
$$

is the conditional expectation of the random variable $\widetilde{F C F}_{t}$, given the information at time $s$.

Classical Expectation What differentiates a classical expectation from a conditional one? With the classical expectation, a real number is determined that gives back the average amount of a random variable. Here, however, it is with the limitation that certain information about this random variable is already available. The information, for example, could relate to whether a new product was successful, or proved to be a flop. Now the investor must determine the average amount of a random variable (we are thinking of cash flows) according to the scenario-twice in our example - to establish the conditional expectation. The conditional expectation will no longer be a single number like in the classical expectation. Instead, it depicts a quantity, which itself is dependent upon the uncertain future: according to the market situation (success or flop), two average cash flows are conceivable. Summing up this observation, we must consider the following: the conditional expectation itself can be a random variable! This differentiates it from the classical expectation, which always depicts a real number.

In our theory of business valuation, we will often be dealing with conditional expectations. One or another reader may thus possibly be interested in getting a 
clean definition and being told about important characteristics of this mathematical concept in detail. We will now disappoint these readers, as we do not intend to explain in further detail what conditional expectations are. Much rather, we will just describe how they are to be used to calculate with. There is one simple reason as to why we are holding back. We have, until now, avoided describing the structure of the underlying uncertainty in detail. If we now wanted to explain how a conditional expectation is defined, we would also have to show how an expectation is calculated altogether and what probability distributions are. But we do not need these details for business valuation. A few simple rules suffice. The entire mathematical apparatus can be left in the background. Likewise, if you want to be a good car driver, you do not have to get involved with the physics of the combustion engine or acquire knowledge about the way transmissions function. It is enough to read the manual, learn the traffic signs, and get some driving experience. Experts must forgive us here for our crude handling. ${ }^{4}$

\subsubsection{Rules}

In the following, we will present five simple rules for calculating conditional expectations. You should make good note of these, as we will be using them again and again.

What is the connection between the conditional expectation and the classical expectation? Our first rule clarifies this.

Rule 1 (Classical Expectation) At time $t=0$, the conditional expectation and the classical expectation coincide,

$$
\mathrm{E}\left[\tilde{X} \mid \mathcal{F}_{0}\right]=\mathrm{E}[\tilde{X}]
$$

The rule shows that the conditional expectation is dealing with a generalization of the classical expectation that comprises more information and other times than the present can take into consideration.

The second rule concerns the linearity, which is supposedly known to our readers for the classical expectation.

Rule 2 (Linearity) For any real numbers $a, b$ and any random variables $\widetilde{X}$ and $\widetilde{Y}$, the following equation applies

$$
\mathrm{E}\left[a \tilde{X}+b \widetilde{Y} \mid \mathcal{F}_{t}\right]=a \mathrm{E}\left[\widetilde{X} \mid \mathcal{F}_{t}\right]+b \mathrm{E}\left[\widetilde{Y} \mid \mathcal{F}_{t}\right]
$$

\footnotetext{
${ }^{4}$ For those who would like to know more, in the last section we give recommendations for further reading.
} 
For technical reasons we need a further rule, which concerns real numbers. We know that these quantities correspond to their expectations. That should now also be true when we are working with conditional expectations.

Rule 3 (Certain Quantity) For the certain quantity 1 we have

$$
\mathrm{E}\left[1 \mid \mathcal{F}_{t}\right]=1 .
$$

An immediate conclusion from this rule affects all quantities, which are not risky. On grounds of the linearity (Rule 2) the following is valid for real numbers $X$,

$$
\mathrm{E}\left[X \mid \mathcal{F}_{t}\right]=X \mathrm{E}\left[1 \mid \mathcal{F}_{t}\right]=X .
$$

It should be kept in mind that condition $\mathcal{F}_{t}$ is not dealing with the information, which we will in fact have at this time. Much rather, it is dealing with the information that we are alleging at time $t$. The fourth rule makes use of our idea that as time advances, we get smarter.

Rule 4 (Iterated Expectation) For $s \leq t$ it always applies

$$
\mathrm{E}\left[\mathrm{E}\left[\widetilde{X} \mid \mathcal{F}_{t}\right] \mid \mathcal{F}_{s}\right]=\mathrm{E}\left[\widetilde{X} \mid \mathcal{F}_{s}\right] .
$$

The rule underlines an important point of our methodology, although it is supposedly the hardest to understand. Nevertheless, there is a very plausible reason behind it. We repeatedly emphasized that we continually find ourselves in the present and are speaking only of our conceptions about the future. The actual development in contrast is not the subject of our observations. Rule 4 illustrates that.

Let us look at our knowledge at time $s$. If $s$ comes before $t$, this knowledge comprises the knowledge that is already accessible to us today, but excludes beyond that the knowledge that we think we will have gained by time $t$. We should know more at time $t$ than at time $s$ : We are indeed operating under the idea, that as time goes on, we do not get more ignorant, but rather smarter. If our overall knowledge is meant to be consistent or rational, it would not make sense to have a completely different knowledge later on if it is built on our today's perceptions of the future.

If we wanted to verbally describe rule 4 , we would perhaps have to say the following: "When we today think about what we will know tomorrow about the day after tomorrow, we will only know what we today already believe to know tomorrow."

Rule 5 (Expectation of Realized Quantities) If a quantity $\widetilde{X}$ is realized at time $t$, then for all other $\widetilde{Y}$

$$
\mathrm{E}\left[\widetilde{X} \widetilde{Y} \mid \mathcal{F}_{t}\right]=\widetilde{X} \mathrm{E}\left[\widetilde{Y} \mid \mathcal{F}_{t}\right] .
$$


Rule 5 illustrates again our methodology that we stay in the present thinking about the future. At time $t$ we will know how the random variable $\widetilde{X}$ will have materialized. $\widetilde{X}$ is then no longer a random variable, but rather a real number. When we then establish the expectation for the quantity $\widetilde{X} \widetilde{Y}$, we can extract $\widetilde{X}$ from the expectation, just as we do so with real numbers: $\widetilde{X}$ is known at time $t$. Rule 5 means, if with the state of information $\mathcal{F}_{t}$ we know the realization of a variable we can treat it in the conditional expectation like a real number: with the conditional expectation known quantities are like certain quantities.

\subsubsection{Example}

The Finite Case To make the handling of conditional expectations and our rules more understandable, let us look at an example. Concentrate on Fig. 2.2.

We are dealing here with a company, which will bear 3 years of payments to its owners. The payments, however, cannot be predicted with certainty.

1. In the first year $(t=1)$, two situations are conceivable, which we want to designate as "up" or "down," as the case may be. From now on we will be using the terms "up" and "down" not with respect to the actual cash flow movements. Rather, up means that the cash flow of the next period is stated at the top of the original value in our figure. Hence, up does not mean that the cash flow increases (as, for example, is clearly visible from $t=2$ to $t=3$ with the cash flow 110 going up to 96.8 ).

Fig. 2.2 Binomial tree in the

193.6 finite example

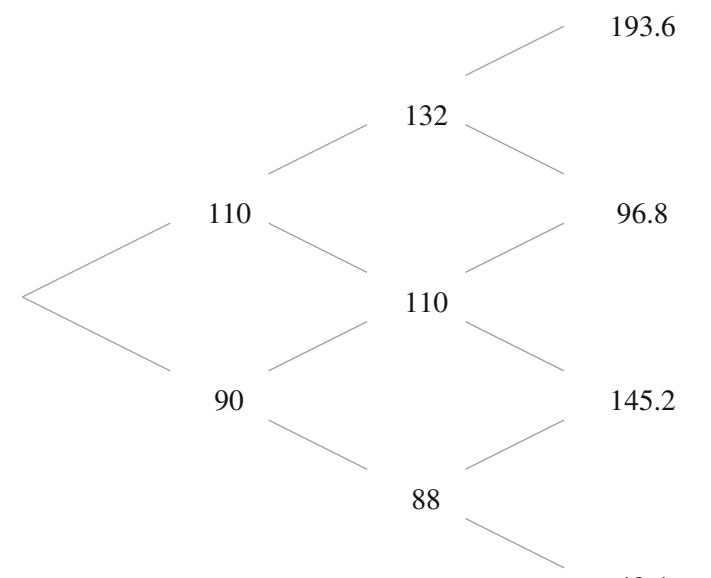

48.4

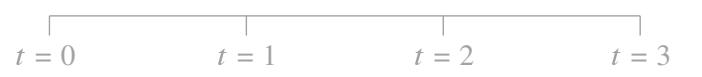


If the development is up, then the payment amounts to 110 , otherwise to 90 . Both states are equally possible. ${ }^{5}$

2. In the second year $(t=2)$, three states are probable.

- If we operate in $t=1$ from up, the development can again proceed up or down. Should chance see to it that the sequence is up-up (abbreviated $u u$ ), then the cash flow in the second year amounts to 132. If the development happens, in contrast, to read up-down (abbreviated $u d$ ), then the owners only get a payment of 110 .

- But if the movement in $t=1$ was down, then things could either turn up, or they could again be down. The development down-up leads at time $t=2$ to payments in the amount of 110, in the case of down-down, the owners only receive 88 .

The three states can also be described differently: Chance twice ensures an unforeseeable development.

- If it goes up twice, then the cash flow amounts to 132 . The probability for this comes to $0.5^{2}=25 \%$.

- If it, in contrast, only goes up once, then the owners get a payment in the amount of 110. Since there are two ways of ending up with this state, their probability comes to $2 \cdot 0.5 \cdot(1-0.5)=50 \%$.

- If, finally, it never goes up, then there is a cash flow of only 88 , and the probability for that is $(1-0.5)^{2}=25 \%$.

3. In the last year $(t=3)$ four states are possible, which can be reached as follows:

- The development proceeds up three times. That leads to a cash flow of 193.6, and namely with a probability of $0.5^{3}=12.5 \%$.

- It only goes up twice. ${ }^{6}$ There are three possible ways for moving into the state with the payment of 96.8 , which is why the possibility for this is $3 \cdot 0.5^{2} \cdot(1-$ $0.5)^{1}=37.5 \%$.

- The development is now only up once. There are also three ways of reaching this state, which is why its probability is $3 \cdot 0.5^{1} \cdot(1-0.5)^{2}=37.5 \%$, and namely with a payment in the amount of 145.2 .

- Finally, it can also always go down. That leads to a cash flow of 48.4 , and namely with a probability of $(1-0.5)^{3}=12.5 \%$.

We could now determine the conditional expectations for every period and in so doing check our rules. As an example let us concentrate on the third-year cash flow

\footnotetext{
${ }^{5}$ In case the actual development will yield a value neither 90 nor 110 our model was wrongly specified. Any decision based on this wrong model will be misleading.

${ }^{6} \mathrm{We}$ continue to use the term "up" even if the path is $u d u=(110,110,96.8)$ and the cash flow in this case in particular goes down from $t=2$ to $t=3$.
} 
and the conceptions, that we will probably have of it at time $t=1$. It is thus dealing with the expression

$$
\mathrm{E}\left[\widetilde{F C F}_{3} \mid \mathcal{F}_{1}\right]
$$

At time $t=1$, two states can have entered in. Let us at first look at the case that we had an up development. From here, three developments are conceivable, namely

- twice up: cash flow 193.6 with probability $25 \%$,

- once up: cash flow 96.8 with probability $50 \%$,

- never up: cash flow 145.2 with probability $25 \%$.

The conditional expectation for the up condition at time $t=1$ is then

$$
0.25 \cdot 193.6+0.5 \cdot 96.8+0.25 \cdot 145.2=133.1
$$

Now, we still have the case to look at that at time $t=1$ we experienced a down development. Three developments are again conceivable from here that by an analogous procedure lead to

$$
0.25 \cdot 96.8+0.5 \cdot 145.2+0.25 \cdot 48.4=108.9
$$

From that we finally end up with

$$
\mathrm{E}\left[\widetilde{F C F}_{3} \mid \mathcal{F}_{1}\right]= \begin{cases}133.1, & \text { if the development in } t=1 \text { is up } \\ 108.9, & \text { if the development in } t=1 \text { is down. }\end{cases}
$$

At this point we discover that $\mathrm{E}\left[\widetilde{F C F}_{3} \mid \mathcal{F}_{1}\right]$ is a random variable, since at time $t=0$ it still cannot be known which of the two conditions will manifest at time $t=1$. $^{7}$

Let us now direct our attention to the unconditional expectation of the random variables $\widetilde{F C F}_{3}$. We can get it directly from

$$
0.125 \cdot 193.6+0.375 \cdot 96.8+0.375 \cdot 145.2+0.125 \cdot 48.4=121 .
$$

\footnotetext{
${ }^{7}$ The attentive reader will ascertain that the conditional expectation of the cash flow $\widetilde{F C F}_{3}$ and the $\widetilde{F C F}_{1}$ are in a close relation to each other. In our payment example, $\mathrm{E}\left[\widetilde{F C F}_{3} \mid \mathcal{F}_{1}\right]=1.1^{2} \cdot \widetilde{F C F}_{1}$ is namely valid, since $1.1^{2} \cdot 110=133.1$ and $1.1^{2} \cdot 90=108.9$. This characteristic is not arbitrarily chosen and will be analyzed more thoroughly in Sect. 3.1.2.
} 
It is, moreover, possible to determine the expectation of the random variables $\mathrm{E}\left[\widetilde{F C F}_{3} \mid \mathcal{F}_{1}\right]$. In order to show that we come to the same result this way, we again have to use our rules. But, we can limit ourselves here to the iterated expectation (rule 4) as well as the classical expectation (rule 1). The following must apply:

$$
\begin{aligned}
\mathrm{E}\left[\mathrm{E}\left[\widetilde{F C F}_{3} \mid \mathcal{F}_{1}\right]\right] & =\mathrm{E}\left[\mathrm{E}\left[\widetilde{F C F}_{3} \mid \mathcal{F}_{1}\right] \mid \mathcal{F}_{0}\right] & & \text { rule 1 } \\
& =\mathrm{E}\left[\widetilde{F C F}_{3} \mid \mathcal{F}_{0}\right] & & \text { rule } 4 \\
& =\mathrm{E}\left[\widetilde{F C F}_{3}\right] . & & \text { rule 1 }
\end{aligned}
$$

And the result is in fact

$$
0.5 \cdot 133.1+0.5 \cdot 108.9=121 .
$$

With that we would like to bring the examination of our rules through the payment example to a close.

The Infinite Case An essential difference from our example that we have been looking at until now is that the firm will now live on indefinitely. We want to suppose that the cash flows follow a binomial process according to Fig. 2.3. Seen from time $t$ onward, the cash flows can move up through time $t+1$ with either factor $u$ or move down with factor $d$, in whereby we will speak of an upward movement in the first case and a downward movement in the second case.

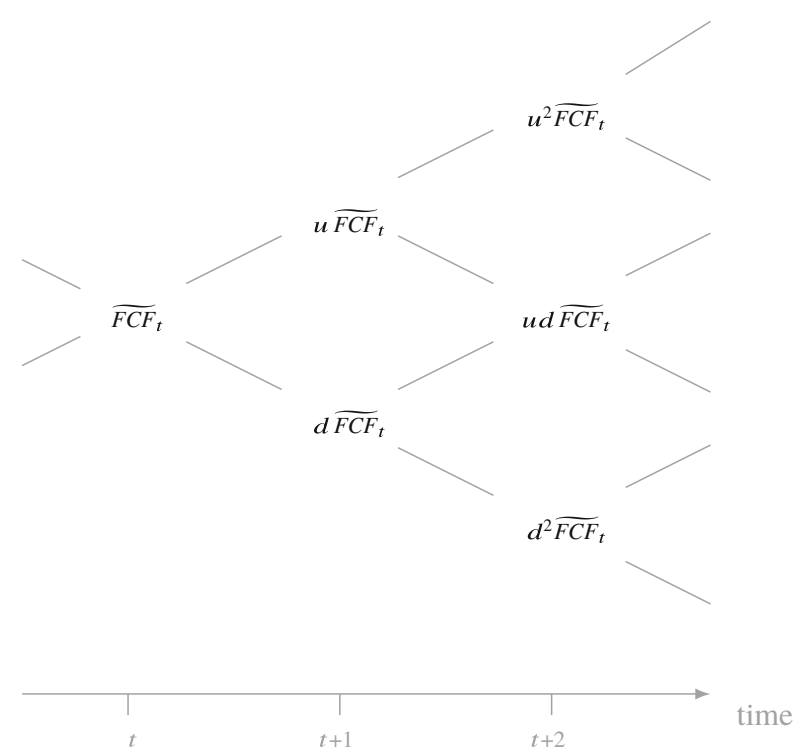

Fig. 2.3 Part of the binomial tree of the infinite example 
For two consecutive times, the following is always valid:

$$
\widetilde{F C F}_{t+1}= \begin{cases}u \widetilde{F C F}_{t} & \text { if the development in } t=1 \text { is up, } \\ d \widetilde{F C F}_{t} & \text { if the development in } t=1 \text { is down. }\end{cases}
$$

We will specify neither $u$ nor $d$ in more detail. We only suppose that they are not dependent upon time and positive. The conditional probabilities at state $\omega$ and time $t+1$ with which the upward and downward movement occur will be denoted by $P_{t+1}(u \mid \omega)$ and $P_{t+1}(d \mid \omega)$. These probabilities do not depend on time $t+1$ and state $\omega$, hence, we suppress both variables from now on.

If under the given assumptions we determine the conditional expectation of a cash flow $\widehat{F C F}_{t+1}$ at time $t$, then the following applies

$$
\begin{aligned}
\mathrm{E}\left[\widetilde{F C F}_{t+1} \mid \mathcal{F}_{t}\right] & =\left(P_{t+1}(u \mid \omega) u \widetilde{F C F}_{t}+P_{t+1}(d \mid \omega) d \widetilde{F C F}_{t}\right) \\
& =\underbrace{(u P(u)+d P(d)}_{=: 1+g} \widetilde{F C F}_{t} .
\end{aligned}
$$

The variable $g$ is thus not dependent on time. Out of this we can immediately derive the relation

$$
\begin{aligned}
\mathrm{E}\left[{\widetilde{F C F_{t}}}_{t} \mid \mathcal{F}_{s}\right] & =\mathrm{E}\left[\ldots \mathrm{E}\left[\widetilde{F C F}_{t} \mid \mathcal{F}_{t-1}\right] \ldots \mid \mathcal{F}_{s}\right] \\
& =(1+g) \ldots(1+g) \widetilde{F C F}_{s} \\
& =(1+g)^{t-s} \widetilde{F C F}_{s}
\end{aligned}
$$

for $s \leq t$ on the basis of rule 4 . We will always, for the subsequent examples, be working from the basis $F C F_{0}=\mathrm{E}\left[\widetilde{F C F}_{1}\right]=100$ and assume that all parameters have been so chosen that $g=0$ is valid. It is also said in this case that the cash flows form a martingale.

\subsubsection{Problems}

1. Look at the example in Fig. 2.4. Assume that the cash flows satisfy

$$
\widetilde{F C F}_{t}=\mathrm{E}\left[{\widetilde{F C F_{t+1}}}_{\mid \mathcal{F}_{t}}\right]
$$

(This particular property of cash flows will become important in the next chapter.) Assume that the up- and down-movements occur with the same probability. Fill in the gaps.

2. The following problem shows that expectations under different probability measures cannot be changed arbitrarily. 


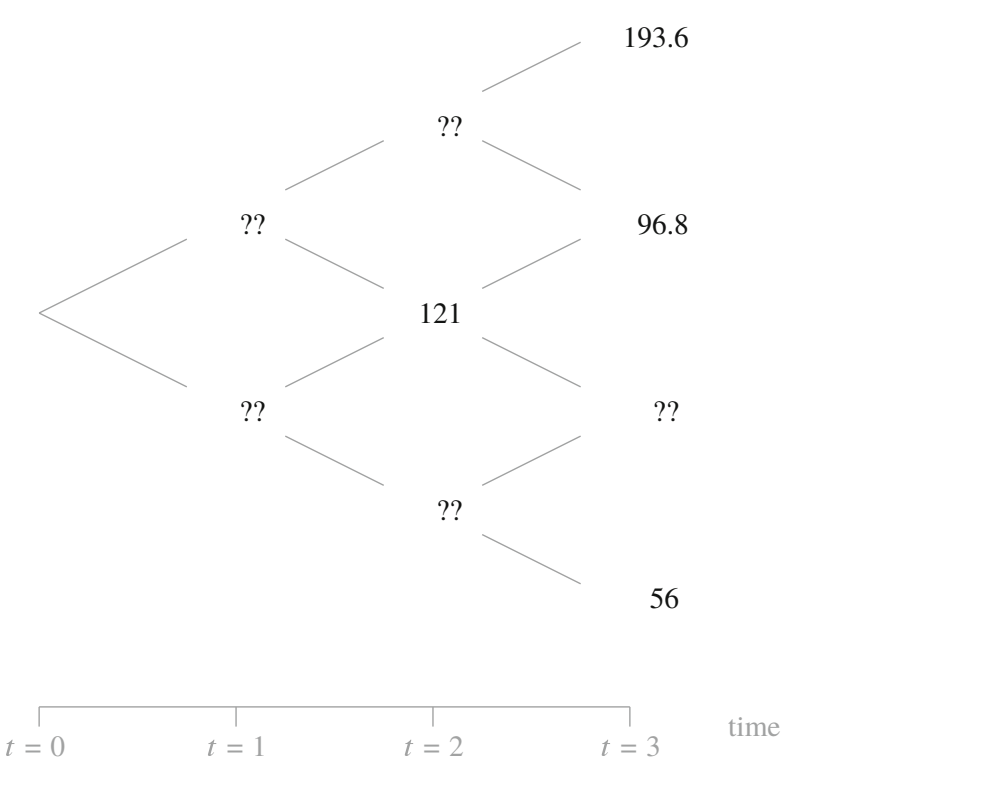

Fig. 2.4 Cash flows in future periods of Problem 1

Go back to the solution of the last problem (see again Fig. 2.4). Let there be two different probabilities: $P$ assigning the same probability to the up- and downmovements and $Q$ that assigns 0.1 to the up- and 0.9 to the down-movement. Verify that

$$
\mathrm{E}\left[\mathrm{E}_{Q}\left[{\widetilde{F C F_{2}}}_{2} \mid \mathcal{F}_{1}\right] \mid \mathcal{F}_{0}\right]=\mathrm{E}_{Q}\left[\mathrm{E}\left[{\widetilde{F C F_{2}}}_{2} \mid \mathcal{F}_{1}\right] \mid \mathcal{F}_{0}\right]
$$

This particular property of probabilities will be necessary when showing that cost of capital are also discount rates. But be careful if the binomial tree distinguishes between up-down and down-up as shown in Fig. 2.5. Verify that in case of Fig. 2.5

$$
\mathrm{E}\left[\mathrm{E}_{Q}\left[\widetilde{F C F}_{2} \mid \mathcal{F}_{1}\right] \mid \mathcal{F}_{0}\right] \neq \mathrm{E}_{Q}\left[\mathrm{E}\left[\widetilde{F C F}_{2} \mid \mathcal{F}_{1}\right] \mid \mathcal{F}_{0}\right]
$$

3. The following problem shows that for any cash flows with constant expectations

$$
\mathrm{E}\left[\widetilde{F C F}_{1}\right]=\mathrm{E}\left[\widetilde{F C F}_{2}\right]=\mathrm{E}\left[\widetilde{F C F}_{3}\right]=F C F_{0}
$$

a binomial model can be established where the conditional expectations of these cash flows satisfy an assumption that was mentioned in Problem 1: 
Fig. 2.5 Cash flows in future

133.1

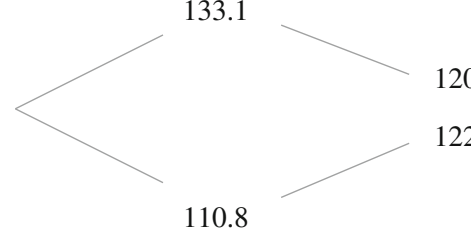

120

122

110.8

100.6

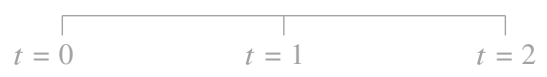

Consider a binomial tree where up- and down-movements occur with the same probability. Let two arbitrary numbers $u, d$ be given such that (this will ensure $g=0$ )

$$
\frac{1}{2} u+\frac{1}{2} d=1, \quad u>d>0 .
$$

Show that the cash flows following the binomial tree in Fig. 2.3 satisfy

$$
\begin{aligned}
& \mathrm{E}\left[\widetilde{F C F}_{3} \mid \mathcal{F}_{2}\right]={\widetilde{F C F_{2}}}, \\
& \mathrm{E}\left[{\widetilde{F C F_{2}}}_{2} \mid \mathcal{F}_{1}\right]={\widetilde{F C F_{1}}}_{1}, \\
& \mathrm{E}\left[{\widetilde{F C F_{1}}}_{1} \mid \mathcal{F}_{0}\right]=F C F_{0} .
\end{aligned}
$$

4. Consider a trinomial tree as in Fig. 2.6. Three movements are possible: "up," "middle," and "down." They occur with the same probability and furthermore (we use $u, d$, and $m$ as in Fig. 2.6)

$$
u d=m^{2} .
$$

What further assumptions on $u, m, d$ are necessary so that in this example

$$
\mathrm{E}\left[\widetilde{F C F}_{2} \mid \mathcal{F}_{1}\right]=\widetilde{F C F}_{1}
$$

holds? 
Fig. 2.6 Trinomial tree of cash flows

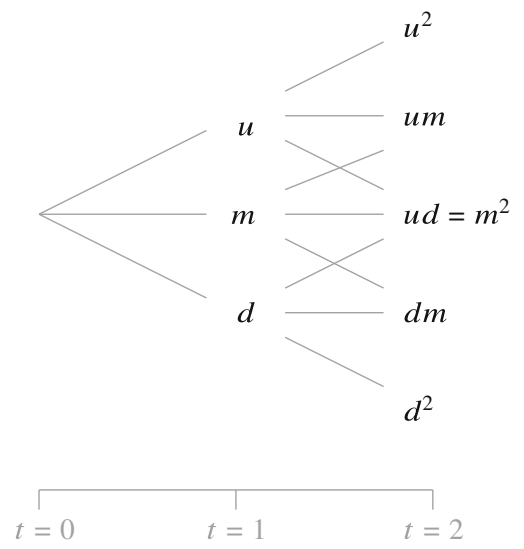

\subsection{A First Glance at Business Values}

In the following section, we will introduce a generalized form of a business valuation concept, which we will regularly use in this book. The connections between business values and cost of capital that will be discussed in this section are to be understood as general in so far as we both want to and still can leave it open as to whether we are analyzing levered or unlevered firms. That is why our procedure still does not demand too polished a use of symbols at this point.

\subsubsection{Valuation Concept}

Every theory is based on assumptions. This is also not different for a theory of business valuation. A central assumption on which further expositions are built up is the following.

Assumption 2.1 (No Free Lunch) The capital market is free of arbitrage.

This assumption is usually specified in finance with the help of an extravagant formalism. We would like to do away with that here, since the effort far outweighs the usefulness and the following does not require such details. We limit ourselves to illustrating the assumption. Arbitrage free means, in loose terms, that no market participant is in the position to make earnings from nothing. Anyone, who has some cash inflows will put up with cash outflows. We will go into the conclusions of this assumption in somewhat more detail.

No Arbitrage and Equilibrium If we assume that the capital market does not allow for a free lunch, we are quite sure that this assumption is indisputable. One is usually convinced that arbitrage opportunities can hold only briefly and 
will be exploited sooner or later so that they disappear. For us, this assumption is straightforward. But, we do not assume that there is an equilibrium on the capital market and we explicitly stress that the existence of an equilibrium is far stronger than the assumption of an arbitrage free market. Any (general) equilibrium will be free of arbitrage, but not vice versa!

The central building block of our theory of business valuation is the so-called fundamental theorem of asset pricing. It can be derived from the concept of no arbitrage. We will not go through the trouble of proving the theorem. But to at least make it plausible, we introduce alternative valuation concepts. While doing so, we limit ourselves for simplicity's sake to the one-period case.

Valuation (in the One-Period Case) Under Certainty Imagine a capital market in which only claims for certain payments are traded that are due in $t=1$. You can think of a firm, which pays dividends at time $t=1$ in the amount of $F C F_{1}$. It is obvious how these securities are to be valued when the capital market is arbitrage free. The certain cash flows are discounted with the riskless interest rate. If we denote the interest rate with $r_{f}$, then equation

$$
V_{0}=\frac{F C F_{1}}{1+r_{f}}
$$

must be valid. Otherwise, one could end up with a strategy that practically comes down to operating a private money pump. And that would be in opposition to the assumption of no free lunch.

If, for instance, the left-hand side of the equation was smaller than the right-hand side, an investor could take out a loan today with the interest rate $r_{f}$ and acquire the firm for the price $V_{0}$. The sum of all payments at time $t=0$ would amount to zero. At time $t=1$, she would retain the cash flows and pay back the loan. And the now remaining account balance would presumably be positive,

$$
F C F_{1}-\left(1+r_{f}\right) V_{0}>0 \text {. }
$$

That is an arbitrage opportunity, and it is exactly such results that we would like to exclude with the Assumption 2.1. ${ }^{8}$

Valuation (in the One-Period Case) Under Uncertainty Future payments are indeed not certain in the world we are looking at. We must thus ask, in what way it can be managed to generalize the relation described in Eq. (2.7). There are three different ways, the last of which deserves our particular attention, to incorporate risk into valuation.

\footnotetext{
${ }^{8}$ We could make a completely analogous argumentation, if the left-hand side of Eq. (2.7) was larger than the right-hand side.
} 
Certainty Equivalent If the cash flows payable at time $t=1$ are uncertain, you could ask about that certain payment at time $t=1$, which the investor finds just as attractive as the risky cash flows. Such a payment is called a certainty equivalent. The certainty equivalent will be discounted with the riskless rate, instead of the expected payments at time $t=1$. The certainty equivalent itself must be determined with the help of a utility function. According to our knowledge, this formulation is rather seldom incurred in practice.

To illustrate the procedure through an example, let us again look at our firm. There are two states of nature in the future. We concentrate solely on the payments due at time $t=1$. Assume then

$$
\widetilde{F C F}_{1}= \begin{cases}110 & \text { if the development in } t=1 \text { is up } \\ 90 & \text { if the development in } t=1 \text { is down }\end{cases}
$$

Assume further, that the two relevant states of nature are equally probable and the riskless interest rate is $r_{f}=5 \%$.

The certainty equivalent is now that payment $S_{1}$ for which the preference relation

$$
S_{1} \sim(110,90: 50 \%, 50 \%)
$$

has been met. The certain payment $S_{1}$ is just as attractive as a lottery, in which one gets 110 or 90 , respectively, with the same probability. That corresponds in the expected utility representation to equation

$$
u\left(S_{1}\right)=\mathrm{E}\left[u\left({\widetilde{F C F_{1}}}_{1}\right)\right]
$$

from which, according to the application of the reverse function, we get

$$
S_{1}=u^{-1}\left(\mathrm{E}\left[u\left(\widetilde{F C F}_{1}\right)\right]\right) .
$$

If $u(x)=\sqrt{x}$ is now the utility function, then the certainty equivalent in our example amounts to

$$
S_{1}=(0.5 \cdot \sqrt{110}+0.5 \cdot \sqrt{90})^{2} \approx 99.75
$$

From that we finally get,

$$
V_{0}=\frac{S_{1}}{1+r_{f}}=\frac{99.75}{1+0.05}=95.00 .
$$

Cost of Capital There is the much more widely spread technique in the valuation practice of raising the riskless interest rate with a risk premium. The sum of both quantities is the cost of capital. In equation (2.7) we then adjust the denominator and not the numerator. 
If the risk premium is named $z$, then the value of the firm in our example results from

$$
V_{0}=\frac{\mathrm{E}\left[\widetilde{F C F}_{1}\right]}{1+r_{f}+z},
$$

and one would come to the same result using the relevant numbers here with a risk premium of $z \approx 0.264 \%$ as with the certainty equivalent method, since

$$
V_{t}=\frac{0.5 \cdot 110+0.5 \cdot 90}{1+0.05+0.00264}=\frac{100}{1.05264}=95.00 \text {. }
$$

Risk-Neutral Probabilities With this third formulation, the riskless interest rate $r_{f}$ is further used to discount with. In the numerator we find an expectation of the risky cash flow. But the expectation is not calculated with the actual estimated subjective probabilities. Instead of that, risk-adjusted probabilities are used, which are also called risk-neutral.

In our example the subjective probabilities for the up, or, as the case may be, down development come to $50 \%$ in each case. It is plain to see that one can express risk aversion with measuring up with a lesser weight and down with a heavier weight.

If the expectation calculated on the basis of risk-neutral probabilities is denoted by $\mathrm{E}_{Q}[\cdot]$, then the valuation formula in our example runs

$$
V_{0}=\frac{\mathrm{E}_{Q}\left[\widetilde{F C F}_{1}\right]}{1+r_{f}} \text {. }
$$

It can be shown that with the relevant numbers here a risk-neutral probability of $48.75 \%$ for up leads to the same result as both concepts already described, since

$$
V_{0}=\frac{0.4875 \cdot 110+0.5125 \cdot 90}{1+0.05}=\frac{99.75}{1.05}=95.00 \text {. }
$$

Several different terms have been used in the literature for this third way. Equivalent martingale measure is also often spoken of, instead of risk-neutral probability.

We now turn to the second approach in more detail and will then be dealing with the last approach.

\subsubsection{Cost of Capital as Conditional Expected Returns}

Discount Rates and Expected Returns In order to get a preliminary notion of cost of capital under uncertainty, let us take a glance in the textbooks. It is often said that cost of capital is an expected return. For example, Copeland et al. (2005, p. 557) 
use the expression "rate of return" instead of "cost of capital," in order to present the valuation concept for a firm. Brealey et al. (2020, p. 228) write explicitly, that the "cost of capital ... is the expected rate of return demanded by investors in the firm's common stock." de Matos (2001, p. 43) also explains that the cost of capital involves expected returns.

However, we also then find the suggestion within the literature to bring the notion of the cost of capital to life somewhat differently. This concerns the idea that the cost of capital should be suitable as discount rate for future cash flows. Brealey et al. (2020, p. 39), for instance, speak of the cost of capital as those figures with which cash flows are to be discounted. There is a related remark in Miles and Ezzell (1980, p. 722), for example, where it is said that "at any time $k, \rho$ is the appropriate rate for discounting the time $i$ expected unlevered cash flow in period $j$ where $\rho$ is referred to as the unlevered cost of capital."

It is not recommended to simply equate expected returns and discount rates. This warning does not easily stand to reason with the critical reader. This will, however, change from now on.

Conditional Expected Returns How can our definition of the cost of capital be generalized, if the future is uncertain? We shift to time $t>0$. The evaluator will have some notions as to the returns at this time. In addition, she sets the reflux one period later in proportion to the employed capital. When the evaluator does this on the basis of the information at time $t$, then the employed capital $\widetilde{V}_{t}$ is not uncertain for her any more. The evaluator can now treat the employed capital like a real number, granted that she always assumes the state of information at time $t$. The evaluator considers the conditional expectation of the reflux $t+1$ against the employed capital $\widetilde{V}_{t}$. Through this understanding of the term cost of capital, a derivation of the valuation equation analogous to (2.1) will be possible. To this end, the following definition of the cost of capital is appropriate.

Definition 2.1 (The Firm's Cost of Capital) The cost of capital $\widetilde{k}_{t}$ of a firm is the conditional expected return

$$
\widetilde{k}_{t}:=\frac{\mathrm{E}\left[\widetilde{F C F}_{t+1}+\widetilde{V}_{t+1} \mid \mathcal{F}_{t}\right]}{\widetilde{V}_{t}}-1 .
$$

Before we move on, we must, however, take note that our cost of capital definition has a possible disadvantage. Look at numerators and denominators separately. In the numerator of Definition 2.1, the expectations of payments at time $t+1$ stand under the condition that the evaluator possesses the state of information of time $t$. One cannot simply assume that these expectations are certain. It is much more likely that these conditional expectations at time $t$ are uncertain, and thus 
depict random variables. If these random variables are now divided by $\widetilde{V}_{t}$, the result is another random variable again, regardless whether $\widetilde{V}_{t}$ is certain or uncertain. But that means that the cost of capital, as it is so defined, constitutes a random variable. Future expected returns from equity as well as debt are all of a sudden uncertain, and that most surely comes as no great surprise for the manager either. Unfortunately, one cannot discount today with quantities, the realization of which is not known at time $t=0$. So, we have a definition of the cost of capital that is not suitable for our intended purpose here!

Deterministic Cost of Capital We will only make it out of this dilemma, if we make an assumption on an heroic scale. One which purports that cost of capital, as defined in Definition 2.1, should be certain. We are plainly and simply taking it for granted that the cost of capital is certain, and will later show that it also makes a suitable discount rate. In other words, those who comprehend the cost of capital as conditional expected return, and assume that it is a certain quantity, may also use them as discount rate.

Our critical colleagues may want to object at this point that the knowledge of future anticipated returns in the valuation of firms depicts all too heroic of an assumption; one which cannot actually be met in real life. To that, we can only answer that it does indeed involve a very large assumption. Only, without this assumption, no one, not even our critics, can prove a valuation equation analogous to Eq. (2.1). ${ }^{9}$ Thus seen, although the assumption is admittedly heroic, it is also indispensable for a theory of business valuation. Those who principally reject it, must also renounce the determination of firms' market values through the use of a DCF approach. Regrettably, we have no other choice in the matter.

The attentive reader will still recall the objection mentioned in the previous section. We had noticed that "time will tell." If we already insinuate that the cost of capital is certain at time $t=0$, then we have taken it for granted that an enormous amount of knowledge is to be gained. Everything that can be ascertained about cost of capital is already known today. At this point we repeat the statement that there is no business to be done without the assumption of certain cost of capital.

Attempts at Other Definitions We would like to point out with all clarity that our definition of cost of capital cannot be made more simple. At first glance nothing seems to speak against buying into Eq. (2.3) and to consider the fact that we are now dealing with uncertainty through an (unconditional) expectation: expression

$$
k_{t} \stackrel{?}{=} \mathrm{E}\left[\frac{\widetilde{F C F}_{t+1}+\widetilde{V}_{t+1}}{\widetilde{V}_{t}}-1\right]
$$

would then describe the cost of capital.

\footnotetext{
${ }^{9}$ One should never say never: We are currently working on a project where cost of capital can be stochastic without violating basic principles of finance. See Kruschwitz and Löffler (2019).
} 
As an academic, you have the freedom to choose your terms as you like. Definitions of cost of capital can be neither true nor false. They are at best suitable or unsuitable. And the preceding definition is by all means unsuitable. To allow for an equation of the form

$$
V_{0}=\frac{\mathrm{E}\left[\widetilde{F C F}_{1}\right]}{1+k}+\frac{\mathrm{E}\left[\widetilde{F C F}_{2}\right]}{(1+k)^{2}}+\ldots
$$

to be obtained it is necessary to detach $\widetilde{V}_{t}$ from the expectation above. But this is impossible for a random variable due to Jensen's inequality. ${ }^{10}$

Even a more refined approach, such as in equation

$$
k_{t} \stackrel{?}{=} \frac{\mathrm{E}\left[\widetilde{F C F}_{t+1}+\widetilde{V}_{t+1}\right]}{\mathrm{E}\left[\widetilde{V}_{t}\right]}-1
$$

does not lead to the kind of results with which we can be satisfied. True, if $k_{t}$ is constant through time, this is easily converted to the following important equation:

$$
V_{0}=\frac{\mathrm{E}\left[\widetilde{F C F}_{1}\right]}{1+k}+\frac{\mathrm{E}\left[\widetilde{F C F}_{2}\right]}{(1+k)^{2}}+\ldots
$$

But we had more in mind for our definition of cost of capital. We were not just thinking about a computational rule, which allows for the current business value to be determined. More importantly, it should be possible to determine future business values. While calculation of $V_{0}$ can now be managed with this definition of cost of capital, we cannot, however, get an equation in the form of

$$
\widetilde{V}_{t}=\frac{\mathrm{E}\left[\overline{F C F}_{t+1} \mid \mathcal{F}_{t}\right]}{1+k}+\frac{\mathrm{E}\left[\overline{F C F}_{t+2} \mid \mathcal{F}_{t}\right]}{(1+k)^{2}}+\ldots
$$

from the definition, since the cost of capital always depicts unconditional expectations. This definition of cost of capital also turns out to be unsuitable for our purposes.

Let us summarize. With a DCF approach, cost of capital is, sensibly enough, taken as conditional expected returns. This idea will be the red thread throughout our presentation. As already stated, we will still assume in the following that the cost

${ }^{10}$ For a random variable $\widetilde{V}_{t}$ that is not deterministic

$$
\frac{1}{\mathrm{E}\left[\widetilde{V}_{t}\right]} \neq \mathrm{E}\left[\frac{1}{\widetilde{V}_{t}}\right]
$$

holds due to Jensen's inequality. A similar result will apply to our attempted definition of cost of capital. 
of capital does not involve random, but rather deterministic quantities. We cannot get any valuation equation without this assumption.

\subsubsection{A First Valuation Equation}

In order to derive the valuation equation, we will use our rules for conditional expectations for the first time. Although this calculation is rather simple, we want to deal with it in some detail. Our intention in doing so is to get our readers more comfortable with the formal usage of the rules.

Theorem 2.1 (Market Value of the Firm) When the cost of capital $k_{t}$ is deterministic, then the firm's value at time t amounts to

$$
\widetilde{V}_{t}=\sum_{s=t+1}^{T} \frac{\mathrm{E}\left[\widetilde{F C F}_{s} \mid \mathcal{F}_{t}\right]}{\left(1+k_{t}\right) \ldots\left(1+k_{s-1}\right)}
$$

The reader used to the product symbol $\Pi$ might prefer the expression

$$
\widetilde{V}_{t}=\sum_{s=t+1}^{T} \frac{\mathrm{E}\left[\overline{F C F}_{s} \mid \mathcal{F}_{t}\right]}{\prod_{\sigma=t}^{s-1}\left(1+k_{\sigma}\right)}
$$

as more compact.

To prove this statement, let us reformulate Definition 2.1 of the cost of capital to

$$
\widetilde{V}_{t}=\frac{\mathrm{E}\left[\widetilde{F C F}_{t+1}+\widetilde{V}_{t+1} \mid \mathcal{F}_{t}\right]}{1+k_{t}} .
$$

The above equation is recursive, as $\widetilde{V}_{t}$ is a function of $\widetilde{V}_{t+1}$. If we use the appropriate relation between $\widetilde{V}_{t+1}$ and $\widetilde{V}_{t+2}$, the result is

$$
\widetilde{V}_{t}=\frac{\mathrm{E}\left[\widetilde{F C F}_{t+1}+\frac{\mathrm{E}\left[\widetilde{F C F}_{t+2}+\widetilde{V}_{t+2} \mid \mathcal{F}_{t+1}\right]}{1+k_{t+1}} \mid \mathcal{F}_{t}\right]}{1+k_{t}} .
$$

Because the cost of capital is deterministic and the conditional expectation is linear, we can reformulate this expression with the help of Rule 2 (linearity) to

$$
\widetilde{V}_{t}=\frac{\mathrm{E}\left[\widetilde{F C F}_{t+1} \mid \mathcal{F}_{t}\right]}{1+k_{t}}+\frac{\mathrm{E}\left[\mathrm{E}\left[\widetilde{F C F}_{t+2} \mid \mathcal{F}_{t+1}\right] \mid \mathcal{F}_{t}\right]}{\left(1+k_{t}\right)\left(1+k_{t+1}\right)}+\frac{\mathrm{E}\left[\mathrm{E}\left[\widetilde{V}_{t+2} \mid \mathcal{F}_{t+1}\right] \mid \mathcal{F}_{t}\right]}{\left(1+k_{t}\right)\left(1+k_{t+1}\right)}
$$


Rule 4 (iterated expectation) allows us to notate the expectation in a more simple form,

$$
\widetilde{V}_{t}=\frac{\mathrm{E}\left[\widetilde{F C F}_{t+1} \mid \mathcal{F}_{t}\right]}{1+k_{t}}+\frac{\mathrm{E}\left[\widetilde{F C F}_{t+2} \mid \mathcal{F}_{t}\right]}{\left(1+k_{t}\right)\left(1+k_{t+1}\right)}+\frac{\mathrm{E}\left[\widetilde{V}_{t+2} \mid \mathcal{F}_{t}\right]}{\left(1+k_{t}\right)\left(1+k_{t+1}\right)}
$$

If we continue this procedure through time $T$, we get

$$
\widetilde{V}_{t}=\frac{\mathrm{E}\left[\widetilde{F C F}_{t+1} \mid \mathcal{F}_{t}\right]}{1+k_{t}}+\ldots+\frac{\mathrm{E}\left[\widetilde{F C F}_{T} \mid \mathcal{F}_{t}\right]}{\left(1+k_{t}\right) \ldots\left(1+k_{T-1}\right)}+\frac{\mathrm{E}\left[\widetilde{V}_{T} \mid \mathcal{F}_{t}\right]}{\left(1+k_{t}\right) \ldots\left(1+k_{T-1}\right)}
$$

On account of the transversality, the last term disappears, giving us

$$
\widetilde{V}_{t}=\sum_{s=t+1}^{T} \frac{\mathrm{E}\left[\overline{F C F}_{s} \mid \mathcal{F}_{t}\right]}{\left(1+k_{t}\right) \ldots\left(1+k_{s-1}\right)}
$$

Under the particular prerequisite, that we are to look at the value of the firm at time $t=0$, it follows out of Theorem 2.1 in relation to Rule 1 (classical expectation)

$$
V_{0}=\sum_{s=1}^{T} \frac{\mathrm{E}\left[\widetilde{F C F}_{s}\right]}{\left(1+k_{0}\right) \ldots\left(1+k_{s-1}\right)}
$$

and finally in the particular case of time-invariant cost of capital

$$
V_{0}=\sum_{t=1}^{T} \frac{\mathrm{E}\left[\widetilde{F C F}_{t}\right]}{(1+k)^{t}}
$$

q.e.d.

\subsubsection{Fundamental Theorem of Asset Pricing}

The idea of an equivalent martingale measure has to do with offering the evaluator other probabilities for the states of nature and thus making her world risk-neutral. That this method is always successful, that there always exist probabilities in which the valuation can be made risk-neutral, is the content of the (first) fundamental theorem of asset pricing.

The fundamental theorem maintains that the investor's subjective probability can be replaced by another probability measure $Q$. We denote the new expectations with $\mathrm{E}_{Q}$. The following statement is valid for them.

Theorem 2.2 (Fundamental Theorem of Asset Pricing) If the capital market is free of arbitrage, then conditional probabilities $Q$ can be chosen to the extent that 
the following equation is valid:

$$
\widetilde{V}_{t}=\frac{\mathrm{E}_{Q}\left[\widetilde{F C F}_{t+1}+\widetilde{V}_{t+1} \mid \mathcal{F}_{t}\right]}{1+r_{f}} .
$$

The fundamental theorem is valid for all conceivable financial claims, for equities as well as debts, for levered as well as unlevered firms.

In Theorem 2.1, we were able to gain a preliminary equation for the valuation of firms out of the definition of the cost of capital. In a completely analogous way, we could show that with the help of risk-neutral probabilities a valuation equation can also be proven. It runs

$$
\widetilde{V}_{t}=\sum_{s=t+1}^{T} \frac{\mathrm{E}_{Q}\left[{\overline{F C F_{s}}}_{s} \mathcal{F}_{t}\right]}{\left(1+r_{f}\right)^{s-t}},
$$

and does not need a new proof.

If we compare the fundamental Theorem 2.2 with Eq. (2.7), we then determine similarities and differences: here as there, we are discounting with the riskless interest rate. Instead of certain payments, we now deal with their conditional expectations. The risk of future payments comes into the equation in so far as we are not working with the subjective probabilities for future states of nature, but rather instead with the so-called risk-neutral probabilities. It deals with a third way, other than certainty equivalents and cost of capital, of incorporating risk into the valuation equation. Again and again throughout this book we will see that the fundamental theorem can be put to practical use.

Risk Neutrality Before we turn to the practical application of the concept, we want to answer the question as to why the probabilities used here are termed as riskless whatsoever. We will make use here as well of our rules for conditional expectations.

For this purpose, we reformulate the fundamental theorem. It goes as

$$
1+r_{f}=\frac{\mathrm{E}_{Q}\left[\widetilde{F C F}_{t+1}+\widetilde{V}_{t+1} \mid \mathcal{F}_{t}\right]}{\widetilde{V}_{t}} .
$$

We know according to Rule 5 (expectation of realized quantities), that the value of the firm at time $t$ is already known and therefore may also be included within the conditional expectation, without changing the result,

$$
1+r_{f}=\mathrm{E}_{Q}\left[\frac{{\widetilde{F C F_{t+1}}}+\widetilde{V}_{t+1}}{\widetilde{V}_{t}} \mid \mathcal{F}_{t}\right]
$$


The one on the left-hand side is certain. On the grounds of rule 3 (certain quantities), we can replace it with its expectation,

$$
r_{f}=\mathrm{E}_{Q}\left[\frac{\overline{F C F}_{t+1}+\widetilde{V}_{t+1}}{\widetilde{V}_{t}} \mid \mathcal{F}_{t}\right]-\mathrm{E}_{Q}\left[1 \mid \mathcal{F}_{t}\right] .
$$

Lastly, we use Rule 2 (linearity) and get

$$
r_{f}=\mathrm{E}_{Q}\left[\frac{\widetilde{F C F}_{t+1}+\widetilde{V}_{t+1}}{\widetilde{V}_{t}}-1 \mid \mathcal{F}_{t}\right] .
$$

This presentation of the fundamental theorem allows for a clear economic interpretation. We look to the returns as an argument for the conditional expectation. An investor attains these if she acquires a security at time $t$, receives the cash flows one period later and immediately afterwards again sells the security. The statement of the last equation then reads that the conditional expected return of this strategy is always riskless, if the risk-neutral probabilities are fallen back upon instead of the subjective probabilities. The designation "risk-neutral probability" for $Q$ relates back to this characteristic.

Flat Term Structure Look again at the fundamental Theorem 2.2. The riskless interest rate in this equation has no time index $t$. We have implicitly insinuated with it that the riskless interest rates are constant over time. This limitation is not necessary and can be easily dropped. If the term structure is not flat, then the riskless interest rate simply attains a time index, and the statement of the fundamental theorem remains further valid.

Uniqueness of $Q$ The question arises whether the mentioned probability $Q$ is unique and what consequences can be drawn if several risk-neutral probabilities exist. We do not want to go into detail here, but the following can be said. For the existence of the risk-neutral probability measure it is completely sufficient that the market is free of arbitrage. The assertion that any claim, so complicated as it may be, is also traded (in this case the market is called complete), is not necessary to prove the fundamental theorem of asset pricing. Admittedly, in this case of an incomplete market one can show that $Q$ need not to be unique. But this is not a problem at least for valuation, since every "possible" probability will lead to one and the same price of the firm.

It is, however, a problem if the firm to be valued is not or not yet traded on the market. In this case the fundamental theorem may not yield one particular value but instead a range of possible prices of the firm. Therefore, a second assumption that is also necessary for DCF valuation is the following. 
Assumption 2.2 (Spanning) The cash flows of an asset to be valued can be perfectly duplicated at the capital market.

Let us discuss this assumption. Again we suppress the formalism required to formulate it in a mathematically precise manner. The assumption requires that the possible cash flow of the company, complicated as it may be, can also be achieved by holding a (possibly involved) portfolio of assets, bonds, derivatives, or any other assets from the capital market. Instead of buying the company, the investor could turn to the capital market and would receive not only a similar, but also the same distribution of cash flows.

It might be questionable, why the investor at all would now buy the company if she can invest in a portfolio of equities and bonds. But we do not care for determining an investor's optimal portfolio (this would require an examination of her utility function). Instead we are decided to value a company by trying to replicate the company's cash flows by a portfolio of traded assets. We stress explicitly here that in this book valuation is a comparison of a company with the capital market. Spanning is necessary to perform this comparison.

\subsubsection{Transversality and Infinite Life Span}

We are working under the assumption in any case that the value of the business closes in on zero, as the firm's end approaches. In the case of a firm with a finite life span, it is a very obvious, even trivial, statement. Beyond time $T$, the cash flows do not flow any more, which is why the value of the firm must disappear. But we also need an analogous business value characteristic when we have a firm with an infinite life span as our basis. In the formally orientated literature, the so-called transversality is spoken of when the discounted business value is heading towards zero with the advance of time. If transversality is not accepted, the danger arises of getting entangled in serious contradictions. ${ }^{11}$

If transversality is responsible for a vanishing firm value if time goes to infinity, it is by no means clear how this condition should be formulated appropriately. One could, for example, use the risk-neutral probability measure and stipulate that

$$
\lim _{T \rightarrow \infty} \frac{\mathrm{E}_{Q}\left[\widetilde{V}_{T}\right]}{\left(1+r_{f}\right)^{T}}=0 .
$$

\footnotetext{
${ }^{11}$ If, for example, a firm that is being looked at finds enough valuable investments over an infinite period, no free cash flows are generated in this case. Since the firm's free cash flow is always at zero, the firm's value (if the transversality condition is not taken into consideration) will also be zero-although the firm is certainly worth more than nothing.
} 
But also the use of the subjective probability could be a possibility. In the first edition of this book we indeed used the specification

$$
\lim _{T \rightarrow \infty} \frac{\mathrm{E}\left[\widetilde{V}_{T}\right]}{(1+k)^{T}}=0 .
$$

Meanwhile, we have figured out that this approach will get us nowhere and that Eq. (2.9) provides the required results. ${ }^{12}$

Assumption 2.3 (Transversality) If the life span of a firm goes to infinity $(T \rightarrow$ $\infty)$, then we have almost-everywhere

$$
\lim _{T \rightarrow \infty} \frac{\mathrm{E}_{Q}\left[\widetilde{V}_{T} \mid \mathcal{F}_{t}\right]}{\left(1+r_{f}\right)^{T-t}}=0 \quad \forall t .
$$

Clearly, this is a mathematical limit. But it is far from easy to interpret a limit correctly in this case. This is because we do not deal with real numbers here but with a limit of random variables, i.e., a limit of functions. Recall that the conditional expectations $\mathrm{E}_{Q}\left[\widehat{F C F}_{T} \mid \mathcal{F}_{t}\right]$ may be uncertain. Now we must take note that there is no one and only definition of a limit of functions. Instead, there are several concepts at hand. ${ }^{13}$

One can show that the so-called almost-everywhere convergence is appropriate. On this basis we state that a sequence of random variables $X_{t}$ "converges" to a random variable $X$ if the following is true: For every state we ask whether

$$
\lim _{T \rightarrow \infty} \widetilde{X}_{t}(\omega)=\widetilde{X}(\omega)
$$

holds. By fixing the state $\omega$ we are no longer dealing with sequences of random variables, but instead with sequences of numbers. Based on this fact we can be certain whether a limit exists and equals a number $\widetilde{X}(\omega)$. However, we do not know how large the set of all such states $\omega$ is. Therefore we say that $\widetilde{X}_{t}$ converges almost-everywhere to $\widetilde{X}$ if the set of such states has probability one. Put differently: "It is certain that the sequence $\widetilde{X}(\omega)$ converges for every $\omega$ to $\widetilde{X}(\omega)$."

\footnotetext{
${ }^{12}$ See in particular Kruschwitz and Löffler (2013).

${ }^{13}$ Convergence can be pointwise, almost-everywhere, in $L^{2}$ or in probability, etc. (see Stoyanov (2013, section 14) for an overview of different convergence concepts for random variables, their interrelations and numerous counterexamples). Notice that further an assumption is necessary that establishes a lower bound $K$ of all cash flows at any time and any state. This lower bound can be arbitrary but need to be a finite number. We believe that this assumption is of technical nature that is not an important economic restriction. The following considerations are-in parts literally-taken from Kruschwitz and Löffler (2013).
} 


\section{Valuation equation (2.11)}

Transversality (2.9) and

Fundamental theorem (2.10)

Fig. 2.7 Transversality is necessary to use a valuation equation with infinite lifetime and accomplish unique enterprise values

In that sense transversality includes the condition (2.9) for an almost-everywhere convergence.

Transversality is not only a technical condition but can be interpreted in an economic meaningful way. Let us assume for a moment that transversality would not be satisfied. Then the fundamental theorem ${ }^{14}$

$$
\widetilde{V}_{t}=\frac{\mathrm{E}_{Q}\left[\widetilde{F C F}_{t+1}+\widetilde{V}_{t+1} \mid \mathcal{F}_{t}\right]}{1+r_{f}}
$$

will even with given cash flows not yield a unique value of the company. Instead, there exists an infinite number of variables $\widetilde{V}_{t}$ that will satisfy the fundamental theorem and could be acknowledged as "value of the company." There is not one but an infinite number of such "values." The valuation of a company using the fundamental theorem is doomed to fail. Transversality is in this sense indispensable.

Figure 2.7 illustrates the interplay between transversality and fundamental theorem on the one hand and a unique firm value on the other hand. Transversality ensures that the fundamental theorem (2.10) and the valuation equation

$$
\widetilde{V}_{t}=\sum_{s=t+1}^{\infty} \frac{\mathrm{E}_{Q}\left[\widetilde{F C F}_{s} \mid \mathcal{F}_{t}\right]}{\left(1+r_{f}\right)^{s-t}}
$$

are equivalent even in the case of infinitely living firms. Those, who presume the fundamental theorem can utilize the valuation equation and vice versa if transversality holds. Exactly this is the meaning of Fig. 2.7.

Let us summarize. The transversality condition 2.3 is necessary if we want to value companies that stay on forever. Forgoing this assumption will lead to inconsistent results.

Notwithstanding we want to emphasize that we do not believe in companies living forever. The main reason for dealing with these peculiar firms is the fact that this assumption simplifies our considerations very much.

\footnotetext{
${ }^{14}$ For details see Kruschwitz and Löffler (2013, theorem 2).
} 


\subsubsection{Problems}

1. Consider the return

$$
\widetilde{r}_{s}:=\frac{\widetilde{F C F}_{s+1}+\widetilde{V}_{s+1}}{V_{s}}-1 .
$$

Assume that cost of capital (conditional expected returns) are deterministic. Show using only the rules of this chapter that for $s_{1}>s_{2}>t$ always

$$
\mathrm{E}\left[\widetilde{r}_{s_{1}} \widetilde{r}_{s_{2}} \mid \mathcal{F}_{t}\right]=\mathrm{E}\left[\widetilde{r}_{s_{1}} \mid \mathcal{F}_{t}\right] \mathrm{E}\left[\widetilde{r}_{s_{2}} \mid \mathcal{F}_{t}\right]
$$

This is also known as independence of returns.

2. Consider the infinite example from Fig. 2.3. Assume that the cost of capital $k$ are constant. Prove that

$$
\widetilde{V}_{t+1}= \begin{cases}u \widetilde{V}_{t} & \text { if up } \\ d \widetilde{V}_{t} & \text { if down. }\end{cases}
$$

Show furthermore that (analogous to (2.6))

$$
\mathrm{E}\left[\widetilde{V}_{t} \mid \mathcal{F}_{s}\right]=\widetilde{V}_{s}
$$

Hint Remember $g=0$.

3. Assume that cost of capital $k$ are deterministic and constant. The firm is infinitely living $(T \rightarrow \infty)$. Assume that the expected cash flows pursue constant growth

$$
\mathrm{E}\left[\widetilde{F C F}_{t+1}\right]=(1+g)^{t} C
$$

for deterministic and constant $g$ with $-1<g<k$ and $C>0$. Find a simple formula for the value of the firm $V_{0}$ using Theorem 2.1. What happens if $g \geq k$ ?

4. This problem will show that without transversality the value of a company might not be unique. To this end assume that we have an infinite number of company values $\widetilde{V}_{t}$ and a sequence of cash flows $\widetilde{F C F}_{t}$ such that the recursion

$$
\widetilde{V}_{t}=\frac{\mathrm{E}_{Q}\left[\widetilde{V}_{t+1}+\widetilde{F C F}_{t+1} \mid \mathcal{F}_{t}\right]}{1+r_{f}}
$$

is satisfied. Transversality shall not hold. Show that the new sequence $\widetilde{V}_{t}^{*}:=$ $\widetilde{V}_{t}+C\left(1+r_{f}\right)^{t}$ with an arbitrary number $C \neq 0$ is also a "valid firm value" in the sense that this $\widetilde{V}_{t}^{*}$ also satisfies the valuation equation. 
5. The following problem is based on Froot and Obstfeld (1991). Let us assume that the cash flows follow a white noise process, i.e.,

$$
\widetilde{F C F}_{t}=\widetilde{F C F}_{0}+\varepsilon_{t},
$$

where $\varepsilon_{t}$ are iid and $\mathrm{E}_{Q}\left[\varepsilon_{t}\right]=g$. Show that then

$$
\widetilde{V}_{t}:=\frac{\widetilde{F C F}_{0}+g}{r_{f}}
$$

are the corresponding firm values because they satisfy the following two characteristics

(a) The recursion equation holds, i.e., $\left(1+r_{f}\right) \widetilde{V}_{t}=\mathrm{E}_{Q}\left[\widetilde{V}_{t+1}+{\widetilde{F C F_{t+1}}} \mid \mathcal{F}_{t}\right]$.

(b) For every $t$ the transversality condition $\lim _{T \rightarrow \infty} \frac{\mathrm{E}_{Q}\left[\widetilde{V}_{T} \mid \mathcal{F}_{t}\right]}{\left(1+r_{f}\right)^{T-t}}=0$ holds.

\subsection{Further Literature}

The concept of the conditional expectation goes back to the work of the Russian mathematician Kolmogorov from the 1930s and is found in every textbook on probability theory. The presentation given in the textbook from Williams (1991) is worth reading. Although it deals only with discrete time, this textbook also gives a very good introduction to the theory of martingale measure. This also applies to Shreve (2004a). Those who want to read more about continuous time models can turn to Karatzas and Shreve (1991), Musiela and Rutkowski (2005), Revuz and Yor (1999) or Shreve (2004b). Though all books are written for students majoring in mathematics.

The fundamental theorem of asset pricing was gradually recognized in several papers and is based on works from Beja (1971), Harrison and Kreps (1979), and Back and Pliska (1991). A proof can also be found in the textbook Musiela and Rutkowski (2005) and in Revuz and Yor (1999).

The definition and determination of cash flows are dealt with in-depth in every textbook on balance sheet analysis; Koller et al. (2015) is a good reference. The topic of the prognosis of future cash flows is unfortunately very often left out, Welch (2014, chapter 20) is a notable exception.

Rapp (2006) and Laitenberger (2006) discuss the question whether a suitable definition of cost of capital can be found that does not need the restriction of nonrandom returns.

Niemann (2004) analyzes uncertain tax rates and their impact on neutrality of tax systems. An overview about national tax codes can be found in Koller et al. (2010, pp. 357-380). (The 2015 edition does not contain a chapter on national tax codes anymore.)

In Husmann et al. (2006) it is shown how several national tax codes can be implemented into our model. 
Transversality is extensively discussed in Kruschwitz and Löffler (2013). A lot of examples, counterexamples as well as proofs can be found there.

Asymmetric taxation with respect to valuation was discussed in Schaefer (1982), Dybvig and Ross (1986), Ross (1987), Dermody and Rockafellar (1991), and recently Becker and Löffler (2016).

\section{References}

Back K, Pliska SR (1991) On the fundamental theorem of asset pricing with an infinite state space. J Math Econ 20:1-18

Becker M, Löffler A (2016) Arbitrage and nonlinear tax scales, No. 205. arqus diskussionsbeitrag. Arbeitskreis Quantitative Steuerlehre

Beja A (1971) The structure of the cost of capital under uncertainty. Rev Econ Stud 38:359-368

Brealey RA, Myers SC, Allen F (2020) Principles of corporate finance, 13th edn. McGraw-Hill, New York

Copeland TE, Weston JF, Shastri K (2005) Financial theory and corporate policy, 4th edn. Pearson, Addison-Wesley, Boston

de Matos JA (2001) Theoretical foundations of corporate finance. Princeton University Press, Princeton

Dermody JC, Rockafellar RT (1991) Cash stream valuation in the face of transaction costs and taxes. Math Financ 1:31-54

Dybvig P, Ross SA (1986) Tax clienteles and asset pricing. J Financ 41:751-62

Froot KA, Obstfeld M (1991) Intrinsic bubbles: the case of stock prices. Am Econ Rev 81:1189_ 1214

Harrison JM, Kreps DM (1979) Martingales and arbitrage in multiperiod securities markets. J. Econ. Theory 20:381-408

Husmann S, Kruschwitz L, Löffler A (2006) WACC and a generalized tax code. Eur J Financ $12: 33-40$

Institut der Wirtschaftsprüfer in Deutschland (2008) IDW Standard: Grundsätze zur Durchführung von Unternehmensbewertungen [IDW S 1] (Stand: 02.04.2008). Die Wirtschaftsprüfung (Suppl) 3:68-89

Karatzas I, Shreve SE (1991) Brownian motion and stochastic calculus, 2nd edn. Springer, New York

Koller T, Goedhart M, Wessels D (2010) Valuation: measuring and managing the value of companies, 5th edn. John Wiley \& Sons, Hoboken

Koller T, Goedhart M, Wessels D (2015) Valuation: measuring and managing the value of companies, 6th edn. John Wiley \& Sons, Hoboken

Kruschwitz L, Löffler A (2013) Transversality and the stochastic nature of cash flows. http://ssrn. com/paper $=2373744$

Kruschwitz L, Löffler A (2019) Stochastic discounting revisited. Mimeo. Freie Universität Berlin

Laitenberger J (2006) Rendite und Kapitalkosten. Z Betriebswirt 76:79-101

Miles JA, Ezzell JR (1980) The weighted average cost of capital, perfect capital markets, and project life: a clarification. J Financ Quant Anal 15:719-730

Musiela M, Rutkowski M (2005) Martingale methods in financial modelling, 2nd edn. Springer, Berlin

Niemann R (2004) Tax rate uncertainty, investment decisions, and tax neutrality. Int Tax Public Financ 11:265-281

Rapp MS (2006) Die arbitragefreie Adjustierung von Diskontierungssätzen bei einfacher Gewinnsteuer. Z Betriebswirtsch Forsch 58:771-806

Revuz D, Yor M (1999) Continuous martingales and Brownian motion, 3rd edn. Springer, Berlin

Ross SA (1987) Arbitrage and martingales with taxation. J Polit Econ 95:371-393 
Schaefer SM (1982) Taxes and security market equilibrium. In: Sharpe WF, Cootner CM (eds) Financial economics: essays in honor of Paul Cootner, Prentice-Hall, Englewood Cliffs, pp $159-178$

Shreve SE (2004a) Stochastic calculus for finance I: the binomial asset pricing model. Springer, New York

Shreve SE (2004b) Stochastic calculus for finance II: continuous-time models. Springer, New York Stoyanov JM (2013) Counterexamples in probability, 3rd edn. Dover Publications, New York

Welch I (2014) Corporate finance, 3rd edn. Ivo Welch

Williams D (1991) Probability with martingales. Cambridge University Press, Cambridge

Open Access This chapter is licensed under the terms of the Creative Commons Attribution 4.0 International License (http://creativecommons.org/licenses/by/4.0/), which permits use, sharing, adaptation, distribution and reproduction in any medium or format, as long as you give appropriate credit to the original author(s) and the source, provide a link to the Creative Commons licence and indicate if changes were made.

The images or other third party material in this chapter are included in the chapter's Creative Commons licence, unless indicated otherwise in a credit line to the material. If material is not included in the chapter's Creative Commons licence and your intended use is not permitted by statutory regulation or exceeds the permitted use, you will need to obtain permission directly from the copyright holder. 